Valduga, M.C.; Moura, R.L. A segurança como elemento da hospitalidade: a presença das Unidades de Polícia Pacificadora como elemento facilitador do desenvolvimento do turismo nas favelas do Rio de Janeiro (RJ). Revista Brasileira de Ecoturismo, São Paulo, v.6, n.3, ago/out-2013, pp.630-647.

\title{
A segurança como elemento da hospitalidade: a presença das Unidades de Polícia Pacificadora como elemento facilitador do desenvolvimento do turismo nas favelas do Rio de Janeiro (RJ)
}

\author{
Security as part of hospitality: the presence of the Pacifying Police Units as \\ facilitator of the development of tourism in the favelas of Rio de Janeiro (RJ)
}

\section{Manoela Carrillo Valduga, Reginaldo Lima de Moura}

\section{RESUMO}

O presente artigo versa acerca da temática do desenvolvimento do Turismo em Favelas a partir da análise das relações de hospitalidade configuradas após a implementação das Unidades de Polícia Pacificadora (UPPs) nas comunidades Dona Marta, ChapéuMangueira, Pavão-Pavãozinho-Cantagalo e Tabajaras - Cabritos, todas localizadas na cidade do Rio de Janeiro. O objetivo da pesquisa é identificar, a partir do olhar da mídia, a influência da hospitalidade doméstica, comercial e pública na conformação da favela como destino turístico. Como procedimento metodológico, optou-se pela busca de informações na mídia impressa diversa em reportagens que abordassem a temática do Turismo em favelas. Como resultado preliminar, infere-se que a prática da hospitalidade nas três categorias abordadas encontra espaço na tessitura social após implementação das UPPs e constitui papel fundamental para o desenvolvimento da favela turística. Desta forma, é importante pensar quais são as ações públicas que os gestores estão desenvolvendo para tornar a favela um produto turístico e, ainda, se as comunidades estudadas estão preparadas para receber futuros fluxos turísticos.

PALAVRAS-CHAVE: Hospitalidade; Turismo em Favelas; Unidades de Polícia Pacificadora; Rio de Janeiro.

\section{ABSTRACT}

This article focus on tourism development in local communities and the analysis of the relations of hospitality configured after the implementation of the Police Pacification Units (UPPs) in Dona Marta, Chapéu-Mangueira, Pavão-Pavãozinho-Cantagalo and Tabajaras - Cabritos - all located in the city of Rio de Janeiro. The goal is to identify, from the look of the media, the influence of domestic hospitality, commercial and public in shaping the favela as a tourist destination. As methodological procedure, we chose to search for information in print different reports that focus on the theme of tourism in the favelas. As a preliminary result, it is inferred that the practice of hospitality in the three categories is addressed in the social space after implementation of UPPs and constitutes fundamental role in the development of tourism. Is important to think about what are the public actions managers are developing to make the favela a tourist product, and, also, if the communities studied are prepared to receive future tourist flows.

KEYWORDS: Hospitality; Tourism in Favelas;. Pacifying Police Units; Rio de Janeiro. 


\section{Introdução}

A discussão apresentada no presente artigo permeia entre os estudos da hospitalidade francesa e americana. A primeira traz os autores do campo da sociologia e da antropologia, que compreende a hospitalidade como algo inerente às relações dos seres humanos. Em contraponto, a corrente americana estuda o comportamento da hospitalidade a partir das trocas monetárias, onde o valor de troca é o que comanda as relações de hospitalidade (CAMARGO, 2004; MORRISON; LASHLEY, 2004). Nas relações sociais que permeiam os encontros nas áreas turísticas das comunidades, lançaremos mão dos pressupostos da acessibilidade, legibilidade e identidade (GRINOVER, 2007) para a compreensão da hospitalidade.

Este trabalho pretende analisar de que forma as relações de hospitalidade nas favelas cariocas mudaram após a instalação das Unidades de Polícia Pacificadora e quais são as perspectivas para a atividade do turismo.

Para dar conta da compreensão das lógicas locais de hospitalidade, são estudados o processo de mudança da prática da hospitalidade urbana nas favelas cariocas; o cenário da hospitalidade comercial nas favelas cariocas; identificação sobre se a prática da hospitalidade social coloca a favela num cenário positivo para o turismo e avaliar se depois da implantação das Unidades de Polícia Pacificadora a favela ficou mais segura, possibilitando, assim, uma perspectiva positiva para o turismo.

As considerações apresentadas no presente trabalho foram feitas por meio da análise de conteúdo de trinta reportagens, prospectadas no período de dezembro de 2008 a julho de 2011, onde se procurou tratar, em linhas gerais, aspectos da hospitalidade urbana, comercial e doméstica; além da questão da segurança. Outra reflexão realizada tratou o modo como essas mudanças estão auxiliando no fomento da atividade turística.

Eventualmente, foram tratadas reportagens referentes a outras comunidades, com a finalidade de agregar informações que legitimam as já apresentadas sobre as favelas analisadas em questão, entretanto a discussão não foi aprofundada.

É importante ressaltar que os apontamentos realizados no presente trabalho são frutos de uma pesquisa que tem como principal análise o discurso midiático. As análises foram centradas na metodologia proposta por Bardin (1977), na sua narrativa "Análise do Conteúdo". A autora ressalta que a análise qualitativa não rejeita toda e qualquer forma de quantificação. Nesses termos, o analista pode/deve recorrer a testes quantitativos para apresentar alguma similaridade nos discursos analisados.

Dessa forma, a pesquisa não irá ater-se a aspectos concernentes à imparcialidade das informações, mas, sim, no que tais informações podem gerar para a população das comunidades analisadas, abrindo, dessa maneira, novos campos de pesquisa para fomentar os estudos da hospitalidade e do turismo.

A imparcialidade da análise está relacionada ao nível de envolvimento que o leitor tem com a mídia divulgadora da notícia, ou até mesmo a forma como a manchete é divulgada. Nesse sentido, percebe-se que realizar uma leitura imparcial dos fatos é algo um tanto quanto utópico. 
Posto isto, foi realizada uma pré-análise de todos os materiais utilizados, assim como de todo material necessário para melhor explicar este fenômeno. O motivo para essa análise, como explica Bardin (1977, p.21), é que na análise qualitativa "é a presença ou a ausência de uma dada característica de conteúdo ou um conjunto de características num determinado fragmento de mensagem que é tomado em consideração".

Dessa forma, a análise das reportagens buscou apoio no referencial teórico. Por último, foi feita uma interpretação referencial, onde as reflexões puderam apontar a existência ou não das questões norteadoras.

$\mathrm{Na}$ análise qualitativa, foram verificadas todas as temáticas das reportagens do período da pesquisa. Nesse sentido, não foi levado em consideração a frequência com a qual o assunto foi abordado; ainda que só fosse relatada uma vez, a matéria foi levada em conta.

\section{Unidade de Polícia Pacificadora e as comunidades investigadas}

Primeiramente, é importante ressaltar que, antes da Unidade de Polícia Pacificadora, outras políticas de segurança já tinham sido implantadas na cidade do Rio de Janeiro, como, por exemplo, o Posto de Policiamento Comunitário (PCC), que foi implantado pela gestão anterior a do atual governador do Estado, Sérgio Cabral, porém sem resultados satisfatórios. O que ocorre é que não temos pesquisas suficientes na área para identificar se esses resultados aconteceram por falta de interesse público ou se realmente no projeto anterior faltava experiência (treinamento) por parte dos agentes da polícia.

O conceito de Unidade de Polícia Pacificadora traz consigo o conceito de "polícia de proximidade". Na verdade, a intenção inicial se dá pela interação com os jovens antes de repressão. A ideia central do programa é tentar realizar uma aproximação com a população das favelas cariocas, principalmente na tentativa de evitar um confronto armado no futuro, com a proposta de recuperar os territórios ocupados por traficantes e milicianos.

Hoje, as Unidades de Polícia Pacificadora já estão presentes nas comunidades do Morro Santa Marta (Botafogo - Zona Sul); Cidade de Deus (Jacarepaguá - Zona Oeste), Jardim Batan (Realengo - Zona Oeste); Babilônia e Chapéu Mangueira (Leme - Zona Sul); Pavão-Pavãozinho e Cantagalo (Copacabana e Ipanema - Zona Sul); Tabajaras e Cabritos (Copacabana - Zona Sul); Providência (Centro); Borel (Tijuca Zona Norte); Andaraí (Tijuca); Formiga (Tijuca); Salgueiro (Tijuca); e Turano (Tijuca). São 200 mil pessoas beneficiadas pelo projeto.

Desenvolvida estrategicamente pela atual gestão da Secretaria de Estado de Segurança, as Unidades de Polícia Pacificadora trabalham com os princípios de polícia comunitária.

É importante ressaltar que a polícia comunitária é um conceito e uma estratégia fundamentada na parceria entre população e as instituições da área de segurança pú- 
blica. O governo do Estado está investindo cerca de $\mathrm{R} \$ 15$ milhões na contratação e qualificação de policiais para que, até 2016 , estejam formados por volta de 60 mil policiais.

Das Unidades de Polícia Pacificadoras apresentadas anteriormente, vamos trabalhar com quatro delas (Tabela 1), todas localizadas na Zona Sul da cidade do Rio de Janeiro.

Tabela 1: Comunidades atendidas e ficha técnica.

Table 1: Communities served and technical records.

\begin{tabular}{|c|c|}
\hline Comunidade & Ficha técnica \\
\hline Dona Marta & $\begin{array}{l}\text { Inauguração: 19/12/2008; Comandante: Capitã Priscilla } \\
\text { Azevedo; Contato: 2334-4099. Efetivo: } 123 \text { PMs; Benefi- } \\
\text { ciados: } 10 \text { mil. Comunidade atendida: Santa Marta; Bair-- } \\
\text { ros: Botafogo e Humaitá; RISP: 01; AISP: 02; PCERJ: } 10^{a} \\
\text { DP; PMERJ: } 2^{\circ} \text { BPM. }\end{array}$ \\
\hline Chapéu-Mangueira & $\begin{array}{l}\text { Inauguração: 10/06/09; Comandante: Capitão Felipe Ma- } \\
\text { galhães dos Reis; Contato: 2334-7341; Efetivo: } 100 \text { PMs; } \\
\text { Beneficiados: } 10 \text { mil. Comunidades atendidas: Babilônia } \\
\text { e Chapéu Mangueira; Bairro: Leme; RISP: 01; AISP: } 19 . \\
\text { PCERJ: } 12^{2} \text { DP; PMERJ: } 19^{\circ} \text { BPM. }\end{array}$ \\
\hline Pavão-Pavãozinho-Cantagalo & $\begin{array}{l}\text { Inauguração: 23/12/2009; Comandante: Capitão Leonar- } \\
\text { do Nogueira; Contato: } 2332-2047 \text { / 2332-2048; Efetivo: } \\
\text { 123; Beneficiados: } 13 \text { mil; Comunidades atendidas: Pa- } \\
\text { vão; Pavãozinho e Cantagalo; Área total das comunida- } \\
\text { des: 0,2 km²; Bairros: Ipanema e Copacabana; Bairros no } \\
\text { raio de } 2 \mathrm{~km}^{2}: \text { Leblon, Ipanema, Lagoa, Copacabana, } \\
\text { Jardim; Botânico, Humaitá e Botafogo; RISP: 01; AISP: } \\
19 \text { e 23, PCERJ: } 13^{\mathrm{a}} \text { DP e } 14^{\mathrm{a}} \text { DP,; PMERJ: } 19^{\circ} \text { BPM e } \\
23^{\circ} \text { BPM. }\end{array}$ \\
\hline Tabajaras - Cabritos & $\begin{array}{l}\text { Inauguração: 14/01/2010; Comandante: Capitão Renato } \\
\text { Sena; Efetivo: } 120 \text { PMs; Beneficiados: } 7 \text { mil; Comunida- } \\
\text { des atendidas:; Ladeira dos Tabajaras, Morro dos Cabri- } \\
\text { tos, Pico do Papagaio e Mangueira (em Botafogo); Área } \\
\text { total das comunidades: } 0,1 \mathrm{~km}^{2} \text {; Bairros: Copacabana e } \\
\text { Botafogo; Bairros no raio de } 2 \mathrm{~km}^{2} \text { : Jardim Botânico, La- } \\
\text { goa, Santa Teresa, Ipanema, Humaitá, Cosme Velho, } \\
\text { Botafogo, Laranjeiras, Copacabana, Urca e Leme; RISP: } \\
01 \text {; AISP: } 02 \text { e 19; PCERJ: } 12^{\mathrm{a}} \text { DP e } 10^{\mathrm{a}} \text { DP; PMERJ: } \\
\text { BPM e } 19^{\circ} \text { BPM. }\end{array}$ \\
\hline
\end{tabular}

Fonte: Elaboração própria. Source: authors. 


\section{O turismo nas favelas após a implementação das UPPs}

A partir da análise das reportagens, o presente artigo propõe que 2008 seja considerado como o ano da implantação; 2009, o ano da expansão; 2010, o ano da consolidação; e, no ano de 2011, foram apresentadas algumas notícias e perspectivas de como se desenvolveu a relação da favela com a Unidade de Polícia Pacificadora.

\section{8: da implantação}

O ano de 2008 foi um ano de muitas mudanças para a cidade do Rio de Janeiro, principalmente para as favelas cariocas. A cidade vivenciava um momento muito complexo no que tange a questão da segurança pública e muitas ações já tinham sido colocadas em prática, porém com resultados insatisfatórios.

O Posto de Policiamento Comunitário (PCC), localizado em algumas favelas do Rio de Janeiro, não tinha apresentado resultados satisfatórios para a Secretaria de Segurança da cidade do Rio de Janeiro. Nesse panorama de insegurança e após vários estudos realizados pela Secretaria de Segurança da atual gestão, surgiu a primeira Unidade de Polícia Pacificadora, implantada na favela Dona Marta, no bairro de Botafogo.

A Unidade de Polícia Pacificadora foi implantada na favela Dona Marta em 19 de dezembro de 2008. Na verdade, o processo de pacificação já estava em prática há, pelo menos, um mês antes da implantação definitiva da Unidade de Polícia Pacificadora. Como foi a primeira favela a ser pacificada, a comunidade Dona Marta serviu de laboratório para a Secretaria de Segurança, que posteriormente a implantou em outras comunidades.

Para o atual Secretário de Segurança, José Mariano Beltrame, "a nova polícia de segurança para as comunidades carentes só funciona se houver a chegada de outros serviços e a presença de Estado, além da polícia". O Secretário ressalta, ainda, que "não adianta implantar um novo policiamento e não dar para o cidadão o restante. Não adianta tirar o 'gatonet' e não colocar a TV cabo formal. E isso já sai da segurança pública".

Esses serviços de infraestrutura, como afirma Grinover (2007), são partes fundamentais da categoria acessibilidade, para que ocorra a prática da hospitalidade. Inicia-se, então, na favela Dona Marta, um processo de hospitalidade urbana, que, segundo Grinover, faz parte de um conjunto de ações para que um local possa ser considerado hospitaleiro.

Grinover (2007 p.142) ressalta, ainda, que "faz parte da cidadania a incorporação de território como espaço não só de habitação, mas também de vivência e convivência". Para o autor, "passear prazerosamente e com segurança" (ibidem) são aspectos necessários para a não segregação dos espaços urbanos, que nos grandes centros urbanos tem se tornado constante.

Como a implantação da Unidade de Polícia Pacificadora ocorreu no final do a- 
A segurança como elemento da hospitalidade: a presença das Unidades de Polícia Pacificadora como elemento facilitador do desenvolvimento do turismo nas favelas do Rio de Janeiro (RJ)

no de 2008, a mídia não deu ênfase na cobertura desse evento. Só no ano seguinte pode-se perceber a dimensão dessa ação por parte da Secretaria de Segurança e do governo do Estado.

\section{9: da expansão}

Após a primeira pacificação do morro Dona Marta, no ano de 2009, ocorreu a expansão das Unidades de Polícia Pacificadora. Aproximadamente dois meses após ser implantada no Dona Marta, estava na hora da Unidade de Polícia Pacificadora chegar à Cidade de Deus, favela localizada em Jacarepaguá. O ano de 2009 pode ser considerado um ano de mudanças: dois dias após a implantação da Unidade de Polícia Pacificadora na Cidade de Deus, foi a vez da comunidade Jardim Batan, localizada no Bairro Realengo.

Quatro meses depois, mais precisamente em 10 de junho de 2009, foi a vez da favela da Babilônia - Chapéu Mangueira, localizada no bairro do Leme. No final do ano de 2009, foi inaugurada mais uma Unidade de Polícia Pacificadora, na favela Cantagalo-Pavão-Pavãozinho.

Visto isso, os reflexos da Unidade de Polícia Pacificadora nas comunidades cariocas começaram a surgir, e a mídia começou a publicar notícias positivas sobre o seu legado nessas comunidades, após a implantação das Unidades de Polícia Pacificadora.

Um trecho da reportagem com o título "Favelas pacificadas preparam a virada da paz" destaca a importância da pacificação para a comunidade. A reportagem noticia que, pela primeira vez em 30 anos, os moradores das comunidades pacificadas passaram o ano novo com segurança.

No Morro da Babilônia, no Leme, os moradores preparam uma recepção especial para um grupo de turistas que terá o privilégio de ver a tradicional queima de fogos da Praia de Copacabana de um ponto inusitado: a 235 metros de altura.

Pode-se aferir que a segurança nas comunidades pacificadas começa a gerar perspectivas de negócios envolvendo a atividade turística.

A reportagem apresentada prospecta o início de uma atividade turística e demonstra, também, a prática da hospitalidade para com os visitantes. De antemão, pode-se perceber que a vivência da hospitalidade ainda se mistura muito com as questões familiares. No trecho analisado, pode-se verificar a hospitalidade pública proposta por Camargo (2004, p.54), que a defende como o "direito de ir-e-vir e, em consequência, de ser atendido em suas expectativas de interação humana".

Nesse sentido, verifica-se que o morador da comunidade analisada em questão vê com "bons olhos" a importância do turista para o crescimento econômico da sua comunidade. 
Outro trecho da mesma reportagem mostra claramente que a população local estava interessada no desenvolvimento turístico da comunidade. A preocupação dos moradores é tão grande que Carlos Pereira, o Palu, vice-presidente da associação de moradores, declarou que "vamos reunir no máximo 40 pessoas nessa primeira experiência, para que tudo dê certinho". Ainda nesse trecho, Palu revela que "quando havia guerra entre traficantes, eu e minha família chegávamos a dormir durante dias seguidos no banheiro de casa".

O envolvimento da comunidade com a Unidade de Polícia Pacificadora ocorreu de forma espontânea em algumas favelas. No morro da Babilônia, por exemplo, a capitã Priscila (carioca de Laranjeiras e torcedora do Flamengo) iniciou um trabalho para consultar os moradores sobre a distribuição de brinquedos. Ainda nessa reportagem, a capitã revela que "essa comunidade é especial por ter um potencial turístico que precisa ser explorado, afinal é Pão de Açúcar de um lado e Corcovado do outro”.

A reportagem aponta, ainda, que "os Moradores do Morro da Babilônia, no Leme, serão os primeiros a participar do 'Albergue o Seu Gringo', projeto que prevê a hospedagem de baixo custo em áreas pacificadas". Visto isso, com apenas um ano de implantação da Unidade de Polícia Pacificadora, a comunidade já começa a colher frutos da atividade turística.

A mesma notícia ainda traz elementos que podemos caracterizar como hospitalidade urbana, proposta por Grinover (2007), no trecho "para o presidente da associação de moradores, José Mário Hilário, 49, a pouca iluminação pública, a falta de água e os 114 barracos de madeira são entrave para o desenvolvimento econômico". Percebe-se nesse trecho que a falta de infraestrutura é um componente importante para que a localidade seja hospitaleira, de acordo com o autor já citado nesse parágrafo. Para ele, esses componentes fazem parte de um conjunto de "serviços que estão presentes na cidade, devendo proporcionar igualdade aos usuários urbanos" (p.135).

Ainda no aspecto referente à hospitalidade, segue o último trecho da reportagem.

Como a área está pacificada, chegou o momento de criar um novo modelo econômico para garantir essa vitória", analisa o guia de turismo Wágner Medeiros, autor do projeto. O sistema de hospedagem é o 'bed and breakfast' (cama e café da manhã). O visitante se hospeda na casa de uma família local, conhece a cidade e paga menos.

Fica claro a questão proposta pelo autor da acessibilidade socioeconômica. Nesse sentido, Grinover leva em consideração "a distribuição de renda" (p.135). Este tipo de projeto dentro das comunidades possibilita esta prática.

A hospitalidade ainda não se constituía tema central da mídia. Entretanto, após analisar as reportagens, é possível perceber esta prática. Com o título "Pavão- 
A segurança como elemento da hospitalidade: a presença das Unidades de Polícia Pacificadora como elemento facilitador do desenvolvimento do turismo nas favelas do Rio de Janeiro (RJ)

Pavãozinho e Cantagalo receberão visitas guiadas", ainda em 2009, mais uma vez as comunidades analisadas estão presentes na mídia.

No trecho "mais do que fazer obras estruturais, queremos levar dignidade e cidadania a essas comunidades", nota-se novamente a questão da falta da infraestrutura, que, para o autor já citado nessa seção, constitui componente fundamental para a hospitalidade urbana, no que se refere à acessibilidade.

O legado da atividade turística já pode ser percebido nesta reportagem, cuja Figura 1 abaixo demonstra esta realidade.

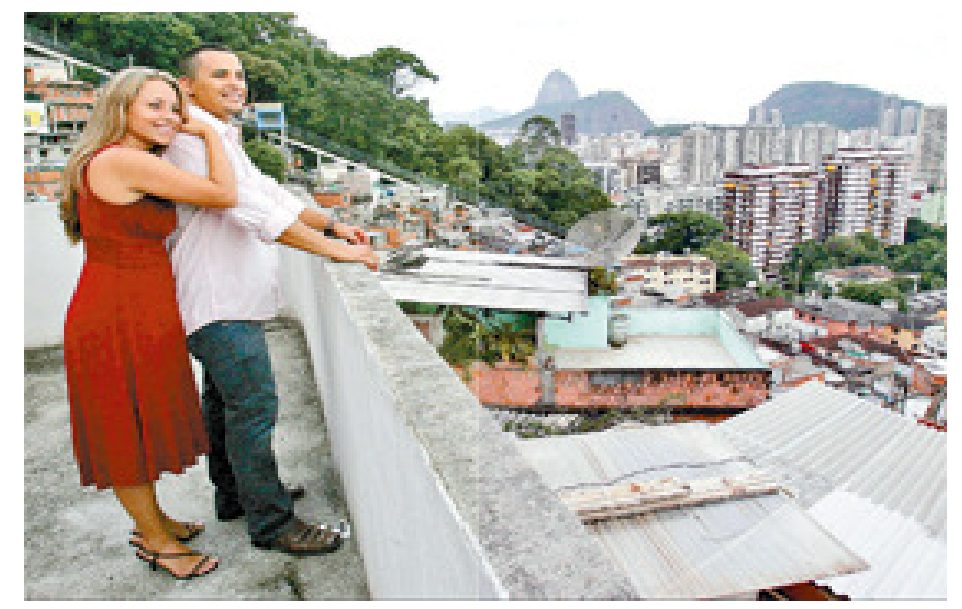

Figura 1: Flávio e Ideni pretendem faturar com o Réveillon no Dona Marta. Fonte: O Dia 29/11/2009. Figure 1: Flavio and Ideni intend to cash in New Year's Eve in the Dona Marta. Source: Journal “O Dia” 29/11/2009.

Uma manchete do site G1, de 23/12/2009, informando que "Cabral inaugura unidade policial para ocupar 2 favelas", novamente revela a questão da acessibilidade socioeconômica proposta por Grinover (2007), que leva em conta a distribuição da renda. Pode-se verificar isso no trecho:

O empresário Daniel Plá anunciou que 30 turistas australianos, franceses e italianos já fizeram reservas para o evento "Réveillon na Laje 2010". Eles assistirão a virada do ano no morro com vista para os fogos de Copacabana. "Toda a renda será revertida para os moradores", declarou o empresário.

Além da questão da expansão da Unidade de Polícia Pacificadora, o ano de 2009 serviu para mostrar que os aspectos referentes à hospitalidade urbana, estudada por Grinover (2007), são percebidos na questão da acessibilidade econômica. Os 
aspectos referentes à hospitalidade comercial foram apresentados como fator fundamental no desenvolvimento da atividade turística das favelas analisadas neste período.

\section{0: Consolidação}

O ano de 2010 serviu para mostrar que a sociedade do Rio de Janeiro vivenciava um novo momento. As reportagens aduzidas aqui refletem uma nova cidade, ou, em contraponto com Ventura (1994), uma única cidade. O autor, ao propor na sua obra "Cidade Partida" que a cidade do Rio de Janeiro se configurava em duas por conta da rede de violência nas comunidades cariocas, não imaginava que a situação das próximas décadas seria diferente.

Em 14 de janeiro de 2010, inicia-se uma nova fase para os moradores do morro dos Tabajaras - Cabritos. Com a proposta inicial de atender três mil moradores, o principal foco do programa da Unidade de Polícia Pacificadora dialoga, de forma satisfatória, com os conceitos apresentados no referencial teórico do presente trabalho, em especial com o autor Grinover (2007). Ao estabelecer em seu estudo a proposta da acessibilidade como uma forma de hospitalidade, o autor deixa claro que a questão da segurança é um dos pontos para o acontecimento do fenômeno.

A reportagem, além de apontar a segurança como principal questão, ressalta a importância de outros serviços básicos. O trecho da matéria apresenta este fato posto pela comunidade, no qual o comerciante Reinaldo revela que "também espera a entrada dos serviços públicos na comunidade". Este fragmento da reportagem mostra, mais uma vez, a questão da acessibilidade proposta por Grinover (2007); nesse sentido, está se referindo a acessibilidade aos serviços públicos, que, para o autor, estão descritos nas características da infraestrutura que compõe um dos aspectos da acessibilidade, na definição da hospitalidade urbana.

Além do aspecto referente à hospitalidade urbana, o trecho abaixo apresenta características que fazem menção ao campo da hospitalidade doméstica, também conceituada no presente trabalho.

\footnotetext{
Rosana, que namora há 10 anos um policial militar, está na corporação há 12. Segundo ela, a receptividade dos moradores a ela é alta. "Ela relatou que uma criança já a convidou para jogar vídeo game em casa e que outra, vendo que ela estava com calor durante a solenidade de inauguração da UPP, Ihe trouxe um copo de água".
}

Nesse sentido, o trecho acima, ao mencionar que a "receptividade dos moradores é alta", dialoga com a teoria do autor Camargo (2004), que propõe a hospitalidade doméstica como um ato voluntário. Para isso, o autor estuda os fenômenos em várias frentes. Para tratar da hospitalidade doméstica, o autor utiliza o termo "receber domés- 
A segurança como elemento da hospitalidade: a presença das Unidades de Polícia Pacificadora como elemento facilitador do desenvolvimento do turismo nas favelas do Rio de Janeiro (RJ)

tico", categoria que trata das questões "sociológicas, psicológicas e antropológicas da hospitalidade" (p.55).

O ano de 2010 foi o ano da consolidação das Unidades de Polícia Pacificadora. Pouco mais de um ano após a instalação da primeira Unidade de Polícia Pacificadora no morro Dona Marta, em Botafogo, os moradores começaram a usufruir dos serviços públicos, que, até então, não eram oferecidos. Essa questão trata da infraestrutura das cidades, que, como proposto por Grinover (2007), é um dos itens para que o fenômeno da hospitalidade possa ocorrer.

Abaixo é citado um trecho da reportagem que caracteriza o argumento estudado pelo autor:

\begin{abstract}
"Com lâmpadas quebradas ou sem nenhuma iluminação, as favelas do Rio vão ganhar um banho de luz este ano. No Santa Marta, em Botafogo, o objetivo é quintuplicar a precária iluminação. Dezenas de vias não têm sequer uma lâmpada funcionando. Serão instalados 571 pontos de luz em 300 ruas até o fim de janeiro. Hoje, existem só 130. "A iniciativa contribui para o lazer e a segurança pública", diz o subsecretário Alexandre Pinto. Pacificada em dezembro de 2008, a favela vê funcionários da Rioluz instalando equipamentos desde dezembro."
\end{abstract}

O título da reportagem "Depois das UPPs, banho de luz" revela que a infraestrutura é um grande problema para os moradores das comunidades estudadas. Para o atual Secretário de Segurança, a iluminação pública é uma questão de "segurança pública" e, ainda, de lazer. Mais uma vez, a hospitalidade urbana, dentro da proposta de Grinover (2007), está sendo legitimada.

Como ano da consolidação, 2010 ainda não tinha terminado e os benefícios das Unidades de Polícia Pacificadora já começaram a aparecer. Em quatro de junho do ano, a reportagem "Pacote turístico para conhecer favela é atração no Rio" já anunciava a favela como um produto turístico seguro, apresentando aspectos referentes à hospitalidade urbana e questões referentes à segurança. Neste sentido, pode-se compreender a reportagem com aspectos referentes à acessibilidade, desta forma, categorizando-a como hospitalidade urbana, segundo o conceito proposto por Grinover (2007).

No final do mesmo mês, com título "Elevadores do Morro do Cantagalo são inaugurados", a reportagem, mais uma vez, aponta o conceito do autor citado no último parágrafo como responsável pela hospitalidade. Dentro da categoria acessibilidade, o transporte de elevador deixa a comunidade, agora, mais acessível (Figura 2) a todos que desejam conhecê-la.

Ainda em 2010, mais precisamente em outubro, a matéria intitulada "Depois das UPPs, favelas ocupadas pelo sabor" apresenta o conceito de hospitalidade dentro da esfera comercial. 


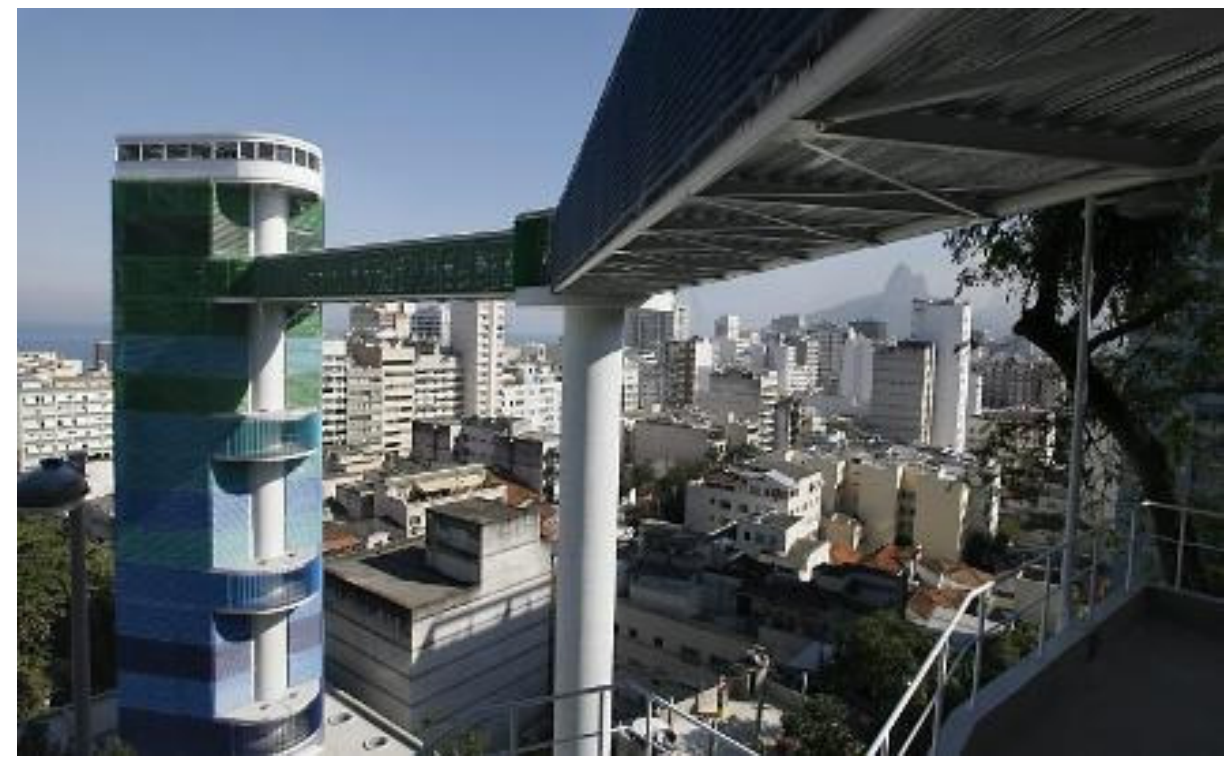

Figura 2: Acessibilidade física - acesso ao Moro do Cantagalo. Fonte: O Extra online, 30/06/2010.

Figure 2: Physical accessibility - access to Morro do Cantagalo. Source: Journal “The Extra online” 30/06/2010.

Nessas pensões, a simplicidade e a simpatia dos proprietários que servem as refeições são melhor entrada. "Turistas já estiveram aqui e preferiram tomar cerveja na laje por conta do visual do porto do Rio. Com a obra, vou ter estrutura para receber mais fregueses" - disse. Ela explicou que, de olho na veia turística que as UPPs representam, já está levando para os profissionais dessas comunidades cursos de formação em gastronomia e manipulação de alimentos.

Nesse sentido, ainda que "a simplicidade e a simpatia" gerem sensações de hospitalidade doméstica, a situação ocorre dentro dos domínios comerciais. Desta forma, pode-se categorizar o fenômeno como hospitalidade comercial dentro da proposta de Morrison e Lashley (2003). Para os autores, o cliente necessita utilizar os serviços sem temer qualquer outra obrigação além da monetária.

O curioso é que a reportagem traz elementos que podem ser percebidos como hospitalidade doméstica. Ao falar que "Turistas já estiveram aqui e preferiram tomar cerveja na laje por conta do visual do porto do Rio", não se pode aferir que se trata de um ato de hospitalidade doméstica; ainda que o serviço seja realizado dentro da residência, há pagamento feito por isso, o que descaracteriza o ato da hospitalidade doméstica proposta por Camargo (2004), que propõe que nesta prática não pode haver nenhum retorno financeiro pela acolhida. 
A segurança como elemento da hospitalidade: a presença das Unidades de Polícia Pacificadora como elemento facilitador do desenvolvimento do turismo nas favelas do Rio de Janeiro (RJ)

\section{1: Panorama e perspectiva}

As reportagens apresentadas aqui são referentes ao ano de 2011, mais precisamente do mês de janeiro até o mês de outubro do ano corrente. Deste modo, será apresentado um panorama de como se encontra o processo de pacificação das comunidades tratadas no presente trabalho, e também analisadas algumas perspectivas para o turismo a partir das matérias prospectadas no período.

Com título "Maravilhosa e a mais estilosa do planeta", a matéria sobre o Rio de Janeiro, como palco para Olimpíadas, apresenta uma nova cidade. No trecho "Além de referências a moda, belezas arquitetônicas e naturais, e à simpatia dos moradores, o rigoroso júri da revista destacou a pacificação das comunidades como ponto positivo para eleger a cidade", pode-se perceber que a hospitalidade dos cariocas já é assunto dos jornais e dos turistas estrangeiros.

Em outro trecho da mesma reportagem, a turista explana que "Os cariocas são solidários, gentis, educados e estão sempre sorrindo, com ar de felicidade estampado no rosto", justifica Sanhita, que ficou muito emocionada com o clima de tranquilidade do morro Dona Marta. A inglesa Kelly Meegan, 47, que estava no mesmo grupo, disse que "estou encantada com a hospitalidade dos cariocas". "Dá vontade de nunca mais ir embora", declarou a designer russa Elena Ablikova, 27, outra turista que acompanhou a visita. Todos os aspectos nessa reportagem são referentes à hospitalidade doméstica proposta por Camargo (2004). O que ocorre, de fato, é uma extrapolação da hospitalidade doméstica para o contexto urbano. O próprio autor apresenta essa problemática nos seus estudos ao revelar que a hospitalidade pública nutre-se da matriz da hospitalidade doméstica. Ao relatar a simpatia dos moradores como algo importante para a prática da atividade turística, percebe-se que a hospitalidade doméstica abrange outros espaços que vão além da configuração doméstica.

O ano de 2011 continuou apresentando perspectivas interessantes para atividade do turismo. Em 30 de janeiro, a matéria "Festas na laje em favelas com UPP fazem sucesso entre turistas no Rio" revela que a segurança, no que diz respeito à infraestrutura, item proposto por Grinover (2006) dentro da categoria acessibilidade, é o que justifica os investimentos para atividade do turismo.

Nesse sentido, pode-se observar que a atividade turística começa a tomar forma dentro das comunidades pacificadas na Zona Sul do Rio de Janeiro. Nota-se tal fenômeno no trecho "A dona do espaço é a simpática aposentada Azelina Viana dos Santos, de 77 anos". O mesmo trecho ressalta, ainda, que "A laje fica no quarto andar de sua casa e virou ponto turístico. Há dois anos, ela realiza em sua laje um réveillon para turistas e convidados com preços a $\mathrm{R} \$ 250$ ". A reportagem apresenta, de forma clara e objetiva, o reflexo da presença da Unidade de Polícia Pacificadora dentro das comunidades cariocas.

Ainda no início do ano de 2011, as comunidades Chapéu Mangueira e o Pavão Pavãozinho começaram a usufruir do legado das Unidades de Polícia Pacificadora. $O$ trecho da reportagem abaixo mostra isso claramente. 
Valdinei Medina, dono de um albergue no Chapéu Mangueira, conta que depois da implantação da Unidade de Polícia Pacificadora (UPP) o turismo melhorou muito no local. "Muitos turistas que visitavam a comunidade sentiam a necessidade de um lugar para se hospedar. O albergue foi mais uma necessidade. Hoje, um albergue em qualquer comunidade pacificada vai ser bom pra todo mundo", disse. Para o australiano Kent Louis, que estuda português, ficar na comunidade é essencial. "Eu gosto de morar aqui por que eu posso falar com brasileiros. É uma comunidade, uma família", contou o turista.

A reportagem mostra um crescimento da atividade do turismo no setor de hospedagem. Depois da instalação da Unidade de Polícia Pacificadora, os moradores donos dos albergues começaram a ganhar mais dinheiro com a hospedagem de turistas.

O principal aspecto referente à hospitalidade da matéria acima remete à hospitalidade urbana, conceituada por Grinover (2007) como a possibilidade de um cidadão local ou turista poder ter acesso ao lugar desejado. Ele propõe que a acessibilidade seja um dos itens necessários para que um local seja considerado hospitaleiro. Para isso, o autor revela que "nas cidades adequadamente identificadas o estrangeiro sente-se acolhido, bem recebido, sabe onde tem que ir, encontra o que procura sem perda de tempo" (GRINOVER, 2007, p.126).

Ainda segundo o autor, a acessibilidade pode ser vista como elemento gerador, como "as possibilidades de acesso dos indivíduos, ou grupos sociais, a certas atividades ou a certos serviços presentes na cidade" (GRINOVER, 2007, p.135).

$\mathrm{O}$ trecho da reportagem anteriormente citado também aborda a hospitalidade pela ótica da identidade, proposta por Grinover (2007) como um elemento de hospitalidade. Percebe-se, nesse caso, que o idioma funciona como um facilitador na comunicação, auxiliando, desta forma, que o processo da hospitalidade ocorra. Nestes casos, percebe-se a necessidade de placas indicativas disponibilizadas em mais de um idioma, para garantir também a acessibilidade.

Outro legado da presença da Unidade de Polícia Pacificadora pode ser notado na reportagem de 24 de abril de 2011. Com título "UPPs no Rio abrigam circuito gastronômico", o propósito é divulgar um roteiro gastronômico em oito comunidades pacificadas no Rio de Janeiro. Os donos dos bares não tem nenhum tipo de propaganda paga, tampouco divulgação em redes sociais. A propaganda é a de "boca em boca". $O$ comerciante revela que "a comida é para matar a fome, sem frescura. Paga-se a partir de $\mathrm{R} \$ 7$ para comer um prato honesto e bem temperado", diz Romero Alves Moreira, dono do restaurante.

No mesmo mês da reportagem citada no último parágrafo, com o título "O perfil do pequeno empresário que une criatividade e tino comercial para levar turistas à favela Dona Marta, na Zona Sul", a favela Dona Marta, mais uma vez, ganha destaque na mídia. A matéria aponta aspecto referente à acessibilidade, categoria estudada por 
Grinover (2007) na hospitalidade urbana. Nota-se isso no trecho "No entanto, depois da instalação de uma Unidade de Polícia Pacificadora (UPP), ele viu crescer o número de grupos interessados em percorrer trilhas, comer em botecos e alcançar em segurança o mirante". Outro aspecto referente à hospitalidade urbana, na categoria identidade, também é demonstrado na reportagem (figura 05). A estátua do cantor Michael Jackson representa a identidade física na categoria proposta acima.

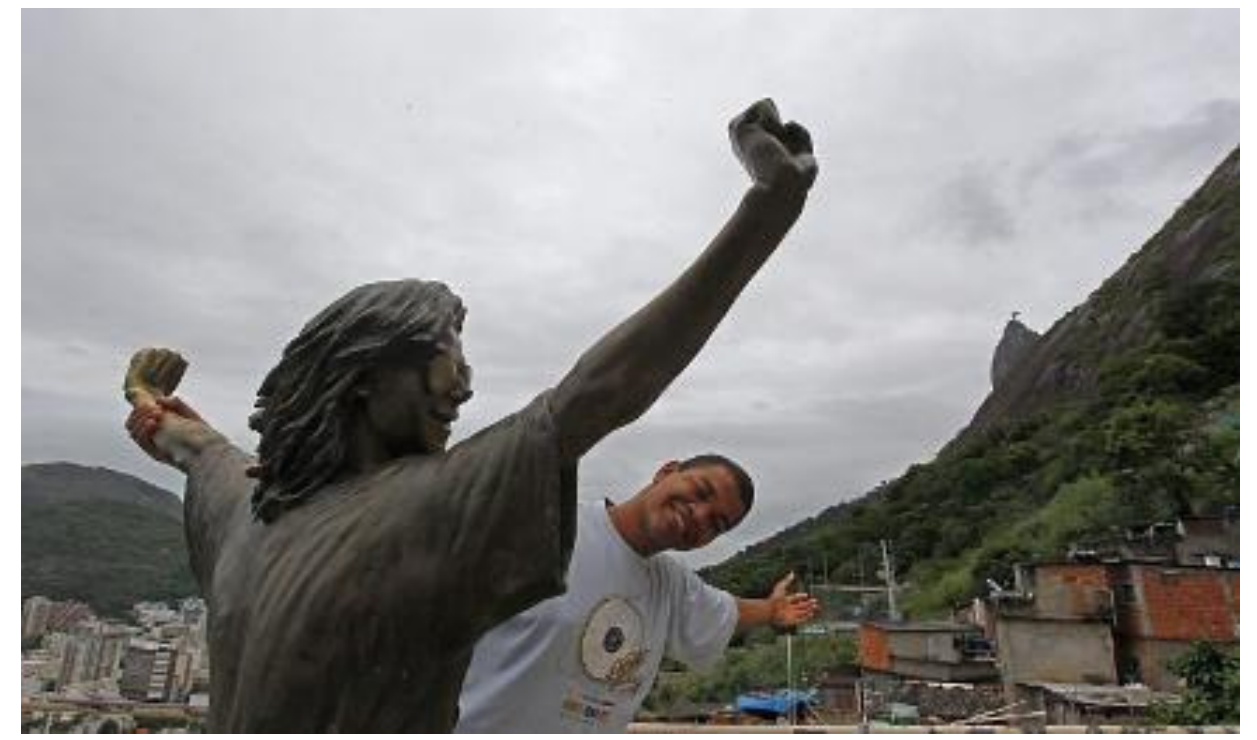

Figura 3: A estátua como identidade cultural da comunidade. Fonte: O Extra online, 30/04/2011.

Figure 3: The statue and cultural identity of the community. Source: Journal “The Extra online”, 30/04/2011.

Mais uma vez, as favelas do Cantagalo, em Ipanema, e Pavão-Pavãozinho, em Copacabana, ganharam destaque na mídia. Em 10 de julho de 2011, com manchete "Comunidades para jovem americano ver", as favelas pacificadas mostraram sua hospitalidade para os turistas. Segue o trecho da reportagem.

"Algo mais consistente do que apenas curiosidade move um novo perfil de turistas estrangeiros que têm visitado favelas cariocas, especialmente as comunidades Cantagalo, em Ipanema, e Pavão e Pavãozinho, em Copacabana, já pacificadas". "Entusiasmados com a visita ao Pavão, Pavãozinho e Cantagalo, alguns deles já deixaram suas impressões por e-mail, que serão lançadas no blog (no ar em agosto), sob os cuidados de um grupo de moradores". "Sem dúvida, foi a minha parte favorita da viagem". "- A favela pode ser debatida sob a ótica de urbanismo, antropologia, ciências sociais e políticas, religião, arquitetura, história e administração de negócios, por exemplo". "Para os estudantes americanos, que fizeram um passeio de cinco horas às três áreas pacificadas, onde comeram feijoada, conversaram com moradores, percorreram ruas, becos e uma trilha, além de assistir a apresentação de funk. 
Notam-se alguns elementos referentes à hospitalidade. No trecho "percorre ruas, becos e uma trilha", verificam-se aspectos no que tange a hospitalidade urbana, na categoria acessibilidade, proposta por Grinover (2007). No trecho "assistir a apresentação de funk e samba", percebe-se a categoria identidade da hospitalidade urbana, também proposta pelo autor.

"No Chapéu Mangueira, bar ganha prêmio e clientes 'do asfalto'", este é o título da reportagem de 12 de julho de 2011. A reportagem apresenta um aspecto referente ao legado do turismo para a favela do Chapéu Mangueira, no bairro do Leme, como também apresenta categoria de análise da hospitalidade comercial abordada por Morrison e Lashley (2004).

Abaixo trecho da reportagem:

\begin{abstract}
Em abril de 2010, ele assumiu o comando do Bar do David, no Morro Chapéu Mangueira, no bairro do Leme, na Zona Sul do Rio de Janeiro. O bar, que existe há cinco anos, era então apenas uma "birosca", diz. 'Comércio é: qualidade, tratamento e preço'. David aponta que a pacificação da favela e a formalização melhoraram seu negócio: "Eu não tinha o mercado que tenho hoje. O movimento é muito maior, e recebo clientes do asfalto e turistas", ressalta.
\end{abstract}

A categoria da hospitalidade comercial proposta por Morrison e Lashley (2004), ou seja, a prática do bom tratamento em ambientes comerciais, pode ser percebida no trecho "Comércio é: qualidade, tratamento e preço". Os autores afirmam que, para a existência dessa categoria da hospitalidade, a mesma "depende da reciprocidade com base na troca monetária .

\title{
Considerações finais
}

A temática apresentada neste artigo permite a reflexão acerca das possibilidades do turismo na transformação socioespacial, com melhorias de infraestrutura e maior igualdade de oportunidades para os sujeitos locais, bem como inclusão dos moradores das comunidades, ora assim chamadas, ora chamadas de favelas, na cidade a qual pertencem.

Tal configuração toma maior proporção quando se trata da cidade do Rio de Janeiro, principal destino turístico do país, que tinha a violência como principal entrave de desenvolvimento turístico.

A pacificação não somente transmite segurança ao turista da "cidade" como abre as possibilidades de expandir o espaço turístico para a favela, com a oferta tradicional do turismo: atrativos turísticos naturais e culturais, gastronomia, eventos, entre- 
A segurança como elemento da hospitalidade: a presença das Unidades de Polícia Pacificadora como elemento facilitador do desenvolvimento do turismo nas favelas do Rio de Janeiro (RJ)

tenimento, transporte e, até mesmo, hospedagem. Desse modo, a favela deixa de ser - local exótico a ser visto de dentro dos jeeps e passa a ser um local de experiência turística.

Das 30 de reportagens analisadas para o presente artigo, poucas mostravam, de fato, o interesse da população autóctone pela hospitalidade nas práticas turísticas. Ainda assim, as matérias discutidas no presente trabalho, conseguiram mostrar as mudanças nas relações de hospitalidade nas atividades turísticas das favelas cariocas após a instalação das Unidades de Polícia Pacificadora.

As análises das reportagens mostram que as comunidades pacificadas querem não só receber bem os turistas, como também poder lucrar com isso. A hospitalidade nessas comunidades acontece de forma muito particular em cada favela. A experiência das práticas de hospitalidade pode ser vivenciada nas comunidades pacificadas, de forma singular. É preciso entender que a favela agora tem, como corrobora Grinover (2006), acessibilidade, legibilidade e identidade.

Nota-se que as favelas cariocas precisam ter a possibilidade de mostrar seu potencial sem perder sua verdadeira identidade. Com isso, também é importante que os comerciantes sejam hospitaleiros para com os turistas não só nas práticas turísticas. É importante para o desenvolvimento do setor que esta prática ocorra sempre de forma natural, sem vínculo direto com aspecto econômico.

Com a implantação das Unidades de Polícia Pacificadora, as reportagens, de uma forma geral, apontaram um indicador favorável para a atividade turística. Nesse sentido, pode-se pensar que a segurança nas favelas cariocas é um dos principais fatores que contribui para o aumento do turismo na região.

No entanto, cabe salientar que somente a segurança não será suficiente para garantir o desenvolvimento local com inclusão social. Políticas públicas de turismo sérias devem ser tomadas para evitar a especulação imobiliária e para qualificar e profissionalizar a prestação de serviços pela comunidade local.

\section{Referências bibliográficas}

BARDIN, L. Análise de Conteúdo. Lisboa, Portugal: Edições 70, 1977.

BARRETTO, M. Relações entre visitantes e visitados: um retrospecto dos estudos socioantropológicos. Turismo e Análise. São Paulo: ECA/USP. v. 15, n 2, p. Nov. 2004.

BARRETTO, M. Turismo, Cultura e Sociedade. Caxias do Sul, RS: Educs, 2006.

BAUMAN, Z. Vida para consumo: a transformação das pessoas em mercadorias, tradução de Carlos Alberto Medeiros. Rio de Janeiro: Jorge Zahar Ed., 2008. 
BAUMAN, Z. Comunidade: a busca por segurança no mundo atual. Rio de Janeiro: Jorge Zahar Ed., 2003.

CAMARGO, L. O. L. Hospitalidade. São Paulo: Aleph, 2004.

CAMPOS, A. Do quilombo à favela: a produção do "espaço criminalizado" no Rio de Janeiro. Rio de Janeiro: Bertrand Brasil, 2005.

CAMPOS, J. R. V. Introdução ao universo da hospitalidade. Campinas: Papirus, 2005.

DENCKER, A. Métodos e técnicas de pesquisa em turismo. 4. Reimp. São Paulo: Futura, 2001.

FREIRE-MEDEIROS, B. A construção da favela carioca como destino turístico. Rio de Janeiro: CPDOC, 2006.

FREIRE-MEDEIROS, B. Favela e seus trânsitos turísticos. Observatório de Inovação do Turismo, v.2, n.2, p 1-13, 2007.

FREIRE-MEDEIROS, B. O Rio de Janeiro que Hollywood inventou. Rio de Janeiro: Jorge Zahar Ed., 2005.

FREIRE-MEDEIROS, B. Gringo na laje: Produção, circulação e consumo da favela turística. Rio de Janeiro: Editora FGV, 2009.

GRINOVER, L. A Hospitalidade, A cidade e o Turismo. São Paulo: Aleph, 2007.

GRINOVER, L. A hospitalidade urbana: acessibilidade, legibilidade e identidade. Revista Hospitalidade, São Paulo, ano III, N.2, P.29,2. Sem. 2006.

LASHLEY, M.; MORRISON. Em busca da hospitalidade: perspectivas para um mundo globalizado. São Paulo: Manole, 2005.

NIELSEN, C. Turismo e mídia: construção e destruição de destinos turísticos. Tradução de Edite Sciulli. São Paulo: Contexto, 2002.

PLENTZ, R. S. Dialética da hospitalidade: caminhos para a humanização. Caxias do Sul, RS: UCS, 2007.

SILVA, L.D. Por que a impressa "gosta de tragédias? Disponível em < http:// www.unb.br/noticias/unbagencia/artigo.php?id=252>. Acesso em: 07 de set. 2010.

SOUZA, J. S. Favela: alegria e dor na cidade. São Paulo: Ed. Senac,2006.

URRY, J. O Olhar do turista: lazer e viagens nas sociedades contemporâneas. São Paulo: Studio Nobel: SESC, 1996.

ZUENIR, V. A cidade partida. São Paulo: Companhia das Letras, 1994. 
Manoela Carrillo Valduga: Universidade Federal Fluminense, Niterói, RJ, Brasil. Email: manoelavalduga@hotmail.com Link para o currículo Lattes: http://lattes.cnpq.br/1175724748253107

Reginaldo Lima de Moura: Universidade Cândido Mendes, Rio de Janeiro, RJ, Brasil.

Email: reginaldolimauff@yahoo.com.br

Link para o currículo Lattes: http://lattes.cnpq.br/7253396866101012

Data de submissão: 30 de junho de 2012

Data de recebimento de correções: 12 de junho de 2013

Data do aceite: 12 de junho de 2013

Avaliado anonimamente 